\title{
THE LANGUAGE LABORATORY AND TEACHING ENGLISH AT THE COLLEGE LEVEL IN JAPAN
}

by Masuko Izumi, Seinen Gakuin University, Sadahiko Ikenra, Fukuoka University of Education and Takeko Itakur, Fukoka jo Gakuin

\author{
Junior College \\ Abstract
}

A recommendation made by the Central Council on Education in Japan states that in foreign language education the main concentration should be placed on the development of practical abilities. Language Laboratory facilities are becoming widespread in Japan as one of the most effective methods of meeting the needs of foreign language training.

In this paper, the first portion deals with the definition of the language laboratory from the technical and the theoretical point of view. It includes the following discussions:

1. The background to the development of the language laboratory.

2. The place of the language laboratory in foreign language education.

3. The basic functions of the language laboratory.

4. The classification of language laboratory facilities.

The second portion presents an analysis of language skills, both audiolingual and visual. The discussion is centered on the problem of which skills are most effectively trained through use of the language laboratory. This analysis is presented in the following order:

1. Language skills.

2. Audio-lingual training of language skills.

a) Development of aural-perception and aural comprehension abilities in English.

b) Development of oral-production ability in English.

Note: This is the second of a two part article. The first part appeared in the Winter 1979 issue. This article is a translated version of a paper presented to Language Laboratory No. II published by the Language Laboratory Association of Japan. 
In the third portion, teaching materials utilized in the language laboratory are discussed in detail. The main points of discussion are as follows:

1. The background of theory necessary for preparing teaching materials.

2. The preparation fo relevant teaching materials.

a) Presentation patterns used in teaching materials.

b) Drill patterns used in teaching materials.

With this presentation of teaching materials through the utilization of the language laboratory, proficiency in audio-lingual skills can be achieved effectively.

\section{The Development of Language Sk:lls and the Language Laboratory Instruction}

1. Outlook on Language

In discussing teaching English at college level, one has to establish a concrete principle as to how one views language. I. B. Carroll defines it as follows:

"A language is a s:ructured system of arbitrary vocal sounds and sequences of sounds which is used, or can be used, in interpersonal communication by an agggregation of human beings, and which rather exhaustively catalogs the things, events, and processes in the human environment."

S. I Hayakawa, who supports the behavioristic theory of language, emphasizes symbolism in language behavior and system as linguistic function in the following way: "Of all forms of symbolism. language is the most highly devcloped, most subtle, and most complicated. It has been pointed out that human beings, by agreement, can make anything stand for anything. Now, human beings have agreed, in the course of centuries of mutual dependency, to let the various noises that they can produce with their lungs, throats, tongues, teeth, and lips systematically stand for specified happenings in their nervous systems. We call that system of agreements language."2

M. A. Pei and F. Gaynor regard language as: "A system of communication by sound, i.e., through the organs of speech and hearing, among human beings of a certain group of community, using vocal symbols possessing arbitrary conventional meanings." "3 Making a distinction between language and writing, L. Bloomficld claims that: "Writing is not language, but merely a way of recording language by means of visible marks." 4

On the basis of those opinions, it is considered that the primary language is the phonetic system for communication and the written 
system is the secondary form of language visualized to transmit information outside the immediate time and spatial element.

\section{The Factors of Language Learning}

C. C. Fries argues in "The Structure of English" that language behavior is stimulus-response behavior, and that the purpose of language learning is basically the acquisition of the phonetic system of language. ${ }^{5}$ Fries has developed the pattern practice method which coincides with B. F. Skinner's theory of learning based on language habit formation by conditioning.

G. A. Miller places emphasis on a code by which information is conveyed. Considering encoding as the action of expression and decoding as the action of understanding, he describes his view of coding system in the following way: "Communication takes place when there is information at one place or person and we want to get it to another place or another person. The first step in getting it there is to encode the information in a set of symbols. The definition of a "code" is quite broad. It may consist of spoken sounds, or written squiggles, the motions of a flagman's arms, the clatter of a telegraph key, the gestures of a deafmute, or whatever other set of symbols is convenient. The coded message travels the intervening space and is decoded by the person who receives it."ø

N. Chomsky refers to language ability in his "Aspects of the Theory of Syntax" in the following nature: "In particular, such speculations have not provided any way to account for or even to express the fundamental fact about the normal use of language, namely the speaker's ability to produce and understand instantly new sentences that are not similar to those previously heard in any physically defined sense or in terms of any notion of frames or classes of elements, nor associated with those previously heard by conditioning, nor obtainable from them by any spot of 'generalization' known to psychology or philosophy. It seems plain that language acquisition is based on the child's discovery of what from a formal point of view is a deep and abstract theory-a generative grammar of his language-many of the concepts and principles of which are only remotely related to experience by long and intricate chains of unconscious quais-inferential steps ..."7 This theory, and also the neo-behavioristic theory of learning, may demonstrate the validity of cognitive learning.

On the other hand, in England where psycholinguistics has played an important role, J. R. Firth and B. Malinowski have claimed importance of the context of situation. This may be further highlighted with the need of contemporary international society to make much of internalization and characterization as well as recognition of International English.

3. The Contents of Language Skills

Now, we will examine language learning in terms of skill, and discuss its factors and stages. W. F. Mackey explains how the four skills are placed in the entire language process and how they are correlated. ${ }^{\theta}$ 


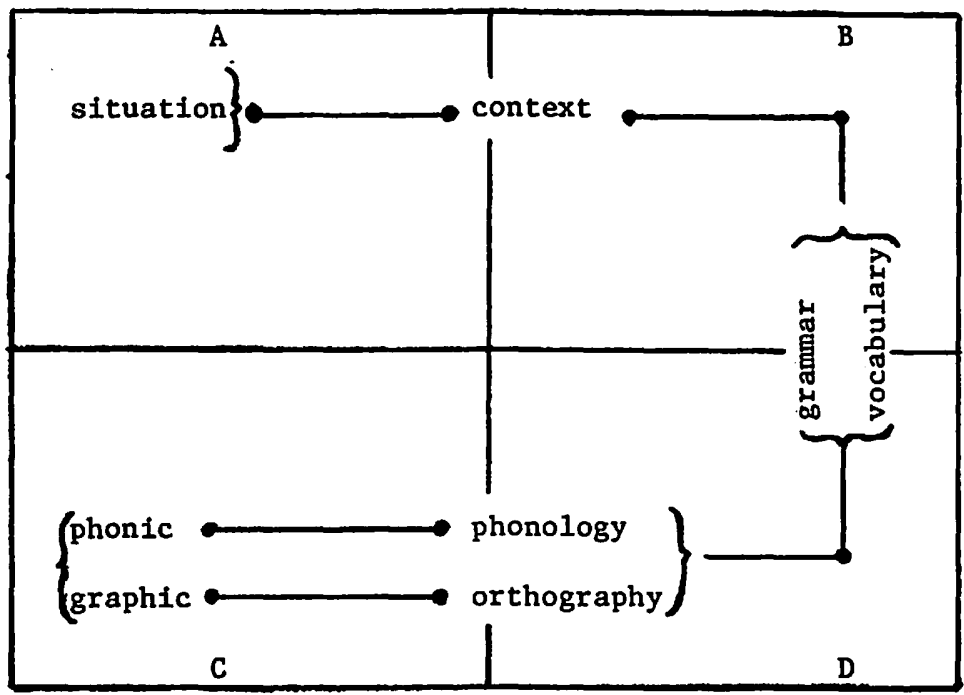

The above diagram shows the relationships among content-substance (A), content-form (B), expression-substance (C), and expression-form (D). Through the medium of 'phonic' and 'phonology', the transition C-D-B-A implies "listening comprehension" and the reverse process A-B-D-C "speaking". Similarly, through the medium of 'graphic' and 'orthography', the transition C-D-B-A implies "reading comprehension" and the reverse A-B-D-C "writing". In both cases, vocabulary and grammar work as a linguistic code.

On the basis of C. C. Fries' conception of total meaning, "meaning" can be divided into two categories: linguistic and cultural. The former is further divided into structural and lexical meaning. The main factors of structure are word order, the function word, and the bound morpheme. Lexical meaning is usually associated with content words. Concerning phonological features, there are two categories: the non-distinctive feature on the phonetic level and the distinctive feature on the phonemic level.

The process of understanding is classified into four stages. The first, discrimination of speech sounds (both non-distinctive and distinctive), and the second involves understandirg of content. The third relates to holding the understood content as knowledge. In the last stage, what one fully appreciates becomes a part of one's character.

Similarly, the process of expression consists of four stages. The first stage concerns mechanical skill. It refers to the skill of expressing automatically meaning according to the structural factors of language under limited learning conditions. The next is the acquisition of linguistic phenomena in the generalized or abstract form. Learning grammar is a 
good example. This is either acquired only as knowledge, or shifted into transfer or creative expression which comes under the third stage. The third is transfer, where the mechanical skill or knowledge acquired in a certain situation is employed in the speech act. On the other hand, transfer between two different languages is possible. That may prevent language learning from being efficient because of negative interference, if there is difference in language structure. In the fourth stage, the skills acquired in the first through third stages are employed for language expression in a situation never experienced before.

4. The Functions of the Language Laboratory and the Training of Speech Sounds

As mentioned in the first chapter, the language laboratory should be basically equipped with machines to prepare teaching materials, reproduce them, visualize them, or record them for effective evaluation by the student himself or the teacher. Thus, the language laboratory appears to be appropriate for training seven skills in listening comprehension and six in oral expression.

\section{A. Training of Listening Comprehension}

\section{1) Discrimination of distinctive features}

Understanding of language transmitted through speech sounds partly functions with discriminating skill on the phonemic level. This is an important factor in order to understand total meaning. According to the investigation of actual conditions, the correlation between phonemic discrimination and listening comprehension rises as training increases. It is also reported that the correlative coefficient was .8 for students who achieved considerably. ${ }^{9}$

2) Discrimination of non-distinctive features

From the structural linguistic point of view, discrimination of nondistinctive features on the phonetic level is considered. Although this may be restricted to particular allophones in the speech act, one must acquire that skill in order to understand a number of speakers with various dialects and diaphones.

What is important to note here, as mentioned in Sataro Uchida's experimental report "On Incorrect Perception Among Plosives", 10 is that incorrect aural perception may occur among plosives even if the position of articulation is different, and that the degree of incorrect perception is even greater if through electronic devices like the language laboratory.

3) Understanding of the meanings of content words in context

The content word includes fairly broad meaning. Meaning in a certain utterance necds to be understood precisely in the context or what 
B. Malinowski refers as the context of situation." Visualization in the language laboratory is useful in this area.

4) Understanding of structure, especially function words and bound morphemes

In most of the cases, the function word or bound morpheme conveys no meaning if it is used by itself. However, it plays an important role in constituting meaning in a coherent utterance. The skill of understanding function words and bound morphemes correctly in the whole structure of utterance is significant.

5) Unifying the meanings understood by phrase

The phrase is an important unit of sentence structure, and is a fundamental unit of conceptual organization in the utterance. Therefore, it is important for skills to be trained in order to grasp meanings phrase by phrase and to understand the contents of the whole utterance by unifying them.

6) Understanding of speech spoken by a native speaker at natural speed

One of the differences between the spoken word and the written word is that there is a certain speed in the spoken word. The rate of speed depends on the situation and differs from one person to another. The listener is passive as far as speed is concerned.

The following are measures of speed by the number of words spoken per minute:

a. Discussion on 'A Common Language' by Markwart and Quirk Chairman 132 words

Markwart 158 words Quirk 162 words

b. English Hour (broadcast on May 31, 1966) 179 words

c. Recreation and Hobbies by W. L. Clark 185 words

d. FEN Weather Forecast (6 A.M., May 26, 1970 ) 140 words

It is desirable that the standard number of words in teaching English on college level is $\mathbf{1 5 0 - 1 6 0}$ per minute.

7) Understanding of Cultural meaning

Cultural meaning denotes a variety of aspects. Thus it can be acquired efficiently by visualization in the language laboratory.

B. Training of oral expression

1) Oral production of distinctive features

Needless to say, clear and precise pronunciation is important, in order for the speaker to have the listener understand his statement. However, that may be restricted to particular allophones within the framework of 
phoneme, and this may support the theory of International English suggested by F. M. Cammack. ${ }^{2}$

2) Use of function words or bound morphemes hension.

This refers to the same, basically, as in the case of aural compre-

3) Selection of content words in the context

The correct selection of content words, as well as cultural meaning, is important, and an efficient drill can be achieved by visualization and appropriate teaching materials in the language laboratory.

4) Correct arrangement of word order

It is necessary for Japanese students studying English to concentrate on English word order which plays an important role in conveying meaning. In comparison with English, the Japanese language places higher emphasis on the particles rather than on the word order.

5) Creative speech by phrase

As previously mentioned, it is important to build up one's ideas phrase by phrase.

6) Speaking at communicable speed

This means not only that the speaker is able to have the listener understand his statement, but that the speaker is able to continue a conversation without making the listener feel under strain. In the case of speaking continuously, $\mathbf{1 3 0}$ words per minute is desirable as a standard.

\section{Notes}

'John B. Carroll, The Study of Language. Harvard Univ. Press, 1953. 25. I. Hayakawa, Language in Thought and Action. George Allen and Unwin Ltd., 1952. p. 27.

${ }^{3}$ Mario A. Pei and Frank Gaynor, Dictionary of Linguistics. Peter Owen, 1965. p. 119.

4Leonard Bloomfield, Language. George Allen and Unwin Ltd., 1955. ${ }^{5}$ Charles C. Fries, The Structure of English. Harcourt, Brace and Co., 1952. p. 34.

-George A. Miller, Language and Communication. McGraw-Hill Book Co., 1963. p. 10.

'Noam Chomsky, Aspects of the Theory of Syntax. The M.I.T. Press, 1965. pp. 57. p. 18.

'William F. Mackey, Language Teaching Analysis. Longmans, 1965.

Ittakura and Gohda, On Aural Comprehension Ability and Reading Ability of English. Language Laboratory, No. 10, 1971.

10Uchida, Sataro, An Acoustic-Phonetic Study of Perceptual Confusions Among Stop Consonants, Academia, No. 45. 46, Nanzan-Gakkai, 1965. 
"Malinowski, Bronislaw, The Problem of Meaning in Primitive Languages, Supplement 1 of C. K. Ogden and I. A. Richards, The Meaning of Meaning. Harcourt, Brace and World, 3rd. ed., rev., 1930.

12Floyd M. Cammack, International English, The Study of Current English Kenkyusha publishing Co., October 1970. pp. 37-43.

\section{Teaching materials in the language laboratory}

In the first chapter, definition was given to the language laboratory. In the second chapter, scope of the language training in the lab was discussed. In this chapter, some theoretical and practical methods for designing teaching materials will be examined.

1. The Theoretical Background for Preparing Teaching Materials

A. The theory of foreign language instruction

In the preceding chapter, the theory of foreign language instruction which underlies language laboratory instruction was discussed in detail. Thus, what will be considered here is directly related to designing teaching materials.

As generally known, there is a controversy between the audio-lingual habit theory, which suggests that language learning is accomplished by language habit formation, and the cognitive code-learning theory, which suggests that language learning is efficiently achieved through cognition and understanding. As mentioned in the second chapter, listening and speaking abilities may be facilitated through the programmed material. Thus, teaching materials should be designed using integrated theories; audio-lingual habit theory and cognitive code-learning theory. Designing those materials will be discussed in more detail in the section 2(A).

B. Languare skills which can be effectively and economically trained by the language laboratory

Concerning the position of the language laboratory in foreign language instruction stated in the first chapter, at least listening and speaking abilities must be achieved in the independent facilities. In which case, feedback function is built in the machine so that the students' learning activities can be evaluated completely through mechanical devices. Generally speaking. however, it is considered that the areas which can be attained through the use of the language laboratory are best left to it, while the instructor takes responsibilities for the areas which cannot be taught fully in the lab. This is the integrated lab mentioned in the first chapter, henceforth the discussion in this chapter will be centered on this integrated lab. The very important problem here is what can be taught in the lab and what cannot. To draw a line of demarcation in this matter, some reliable data from the investigation of the actual circumstances is needed. However, the standard line can be drawn to some extent if considered and inferred from the functional characteristics of the lab and the teaching objectives. 


\section{1) Phoneme}

The phoneme can be divided into two categories: the segmental phoneme related to the individual phone, and the supra-segmental phoneme related to intonation. From the technical point of view, skills may be categorized further into receptive skills and productive skills.

In general, the training of receptive skills is more easily accomplished in the lab than that of productive skills. And also, the supra-segmental phoneme is less difficult in lab work than the segmental phoneme. Receptive skills for phonemes can be attained effectively by contrastive presentation through the lab. The problem is that receptive skills are not regarded as equal to productive skills. Even if $/ s /$ and $/ 2 /$ have been distinguished aurally, it does not necessarily assure that $/ \mathrm{s} /$ and $/ 2 /$ are both correctly being pronounced. It must be also noted that, if the training of productive skills for segmental phonemes is all conducted in the language laboratory, some phones might be confused with phones similar to Japanese sounds and might be incorrectly acquired. Therefore, it is necessary to examine beforehand which phonemes can be decoded clearly and precisely through the language laboratory and which phonemes cannot.

2) Morpheme

a. content word

This is an area which is most easily achieved in the language laboratory. Generally, the college student has more visual vocabulary than audio vocabulary, and the training for audio vocabulary can be effectively done in the lab.

b. bound morpheme and function word

Teaching bound morphemes is different in the language laboratory because it may involve aural perception of segmental phonemes and the phones in the final position of the word. Since the function word is usually uttered in weak form and a part of it occasionally may be left out, it is difficult to teach only through the lab. Like the foregoing productive skills for segmental phonemes, teaching these areas cannot be cntrusted only to the lab.

\section{3) Word-order}

Teaching word-order is effectively done in the lab.

4) Creative speech

$U_{p}$ to this point, the role of the language laboratory in foreign language instruction does not seem to be highly evaluated. One of the reasons may be that there were not sufficient teaching materials for training the skills of variation in speech habit and selection of appropriate types of speech on all levels. Creative speech may be taught to some extent in the lab if teaching materials are carefully designed and programmed with visual aids. However, as in (1) and (2h). creative speech is another area which cannot be completely attaincd in the lab. 
In summary, the ultimate success of the language laboratory instruction will depend on whether evaluation through the feedback function can be given to the student precisely and immediately. Therefore, the higher an index of feedback for the student's receptive skills for phonemes or understanding of grammatical structure, the greater becomes the effect of language laboratory instruction. In addition, if the immediate feedback in the lab system is developed for various objectives in the future, feasibility of the language laboratory instruction seems to further expend.

One of the most important features of the lab, as mentioned in the first chapter, is to make individual learning possible and to stimulate the student's enthusiasm. Taking these into account, what one has to know in designing teaching materials is the actual status of the student's English proficiency.

The following data is one of the references on the student's English proficiency. R. Lado's "The Test of Aural Comprehension"' and "The Test of Aural Perception in English for Japanese Students" ${ }^{2}$ were given to $\mathbf{1 5 0}$ freshmen chosen at random from three universities. The result showed that the average scores on these tests were 53 to $59,{ }^{3}$ far below the required minimum score of 70 set up by $R$. Lado.

By measuring the student's audio-lingual skill, the following three points are clarified, regarding the kinds of language objectives incorporated in teaching materials and presentation of teaching materials:

a. able to offer teaching materials with the proper degree of difficulty,

b. able to complement and reinforce the area which the student is not familiar with,

c. able to leave out the area which the student has already acquired.

The above draws attention to what kind of teaching materials should be provided to a certain group of students. It is also suggested that, by use of the program selection system, it is possible for several sub-groups within one group to learn individual according to differences in achievement.

Teaching materials in the lab should be neither so easy that the student is bored; nor so difficult that he feels discouraged. It is desirable, first of all, that teaching materials should be attractive to the student so that he can engage in learning in the lab willingly and seriously. For that purpose, it is necessary to investigate the student's abilities of aural perception and oral production in the target language.

2. Some Pracical Methods of Designing Teaching Materials

A. Methods for presentation of teaching materials

1) Deductive rather than inductive

Teaching objectives must be clearly explained prior to drills. First the objectives and grammatical rules are concise!y presented, and then drills are given. As for the number of drills to be provided for one teaching unit, E. Stack claims that it is necessary to give the student at least a 
sequence of eight examples in order that a sentence pattern be acquired.4 And further, it seems suitable that these eight examples are divided into two different types of drills, with four examples for each.

2) Presentation with the perception of meaning involved

Since a simple exercise by repetition often falls into dull and meaningless activity, effort must be made in presenting teaching materials. The constant change of the slot $^{3}$ position in the sentence, or the use of visual aids may work out well as a practical method for exercises which involve the perception of meaning. The use of Japanese as a cue is also a simple and effective method, although an element of translation is added to this exercise.

\section{3) Exercises in the form of four phase drill}

For aural perception drills, recorded tapes that have no pause may be used though, strictly speaking, tapes of that sort are not suitable as teaching materials in the lab. However, the presentation of teaching materials which have the pause for the student's utterance is desirable for the purpose of training abilities of both aural comprehension and oral production. Especially for training productive skills, the exercise in the form of four phase drill; stimulus response, positive response reinforcement is mostly employed. Here, the length of the pause for response and reinforcement is very important. The problems caused by its shortness or the lengthy pause often create psychological anxiety.

\section{4) Arrangement by smallest step}

This is fundamental for programmed learning, but there seems to be various problems as to what the smallest step actually is. It may be considered that the range of the smallest step is defined by the student's actual status of learning as is its degree at the transition from the easy to the difficult step. From the standpoint of teaching effect, the optimum step must be also taken into account, since the smallest step does not always lead to the achievement of objectives.

B. Types of drills to be used in teaching materials

There are various types of drills to be used in teaching materials. The basic type is pattern practice introduced by E. Stack, ${ }^{\circ}$ R. Lado, ${ }^{7} \mathrm{~N}$. Brooks, ${ }^{\circ}$ J. Etmekjian, ${ }^{9}$ and T. Yamaga. ${ }^{10} \mathrm{~A}$ detailed analysis of pattern practice is found in "A Study of Pattern Practice Classification" by $M$. Suenobu."

1) Repetition drill

a. simple repetition: It refers to the repetition of a word, a phrase, or a sentence, and is the simplest type of drill. Repetition drill cannot be effectively accomplished unless it involves the perception of meaning.

b. mimicry-memorization: If a repetition drill is given with no visual devices or texts, the student tries to concentrate on the meaning of the sentence. Thus, this type of drill is considered to be a higher level of exercise than (a), because perception of meaning is involved. 
Repetition drills are used for all sorts of teaching objectives and are effective for the training of receptive skills for phonemes and productive skills if combined especially with contrastive technique based on minimal pairs. Should there be no visual devices, the length of the sentence which can be memorized and repeated-memory span-is also an important matter to be considered.

2) Substitution drill

a. simple substitution: Only one word is replaced in the sentence, and the place of that word is learned in advance. As soon as the student hears a cue, he shifts the whole sentence and completes it by substitution. Although this drill is suitable for expansion of vocabulary and comprehension of sentence structure, the perception of meaning tends to be neglected.

b. multiple substitution: Two or more words are replaced in the sentence. The student has to immediately decide where the cues to be substituted are supposed to be placed in the sentence. In this type of drill, the perception of meaning is involved.

c. substitution in variable slot: The place of the word to be replaced in the sentence shifts constantly, and sometimes other elements of sentence structure (e.g., tense) may also be changed because of that word. This is an even higher level of exercise than (b). This type of drill becomes both advantageous and disadvantageous for the student because the learning objectives cannot be recognized easily during the course of drilling.

d. substitution and translation: A cue is given in japanese. Although it may be considered that the use of Japanese as a cue breaks the flow of English rhythm, there is the advantage that meaning is perceived precisely and easily. This should be regarded rather as a kind of exercise in translation, not just that Japanesc has been used for convenience' sake.

3) Transformation drill

This drill is suited to all types of exercises on sentence structure and vocabulary. Most of the following types are ideal drills that always require the student to understand sentence structure or meaning.

a. permutation: The places of constituents in the sentence are interchanged.

b. addition: Another constituent is added to the sentence or to a constituent in the sentence.

c. synthesis: Exercises in synthesis between two sentences or in the paragraph.

4) Contextualized conversation drill

Pattern practice is the most essential drill in the language laboratory learning. Drills should be provided in modified forms stated above so that the sentence patterns the student learns can be used in a real situation.

a. question and answer: This is a drill to demand answers to questions or vice versa. To give a language situation, a short story or a general 
matter of everyday life is depicted as: a topic. Also, it is desirable to use visual devices for this type of drill. The student should be drilled not only on how to answer but also on how to ask a question.

There are other types of drills such as dialogue, restatement, and so forth. In the case of repetition, substitution, or transformation, the sentence patterns to be used are pre-set. On the other hand, in drills like dialogue or restatement, no pattern has been set up. The student is trained to utilize the patterns he has acquired by choosing them freely and immediately. Teaching materials for this drill seem to have been developed least of all.

5) Translation drill

Japanese sentences are successively translated into English and vice versa. This type of drill can be given not only for a lower level but also for a higher level of exercise.

By combining the most suitable patterns for each teaching objective and designing teaching materials based on learning theories, we can carry out effective instruction without having the students become bored and impatient.

\section{Notes}

'Robert Lado, The Test of Aural Comprehension. English Language Institute, University of Michigan.

${ }^{2}$ Robert Lado, The Test of Aural Perception in English for Japanese Students. English Language Institute, University of Michigan.

${ }^{3}$ The results are based on the data obtained from the tests given to 50 first year students of Seinan Gakuin University, 50 first year students of Fukuoka University of Education and 50 first year students of Fukuoka Jo Gakuin Junior College, respectively.

${ }^{4}$ Edward Stack, The Language Lahoratory and Modern Language Teaching. Oxford University Press, 1960, p. 32.

"Slot" is the word used by lames Etmekiian in the following definition, "The place of the word for which a substitution is made is called the "slot":' Pattern Drills in Langunge Teaching. New York University Press, 1966, p. 9.

BEdward Stack, pp. 7-47.

7Robert Lado, Language Teaching-A Scientic Approach. McGrawHill, New York, 1964, pp. 103-113.

@Nelson Brooks, Language and Lanzuage Learning. Harcourt, Brace and World, Inc., 1964, pp. 152-163.

9/ames Etmekiian, pp. 7-40.

10Tamotsu Yamaga, Pattern Practice and Contrast. Kairyudo, Tokyo, 1956.

"Mineo Suenobu, A Studv of Pattern Practice Classification. language Laboratory No. 8, 1968, pp. 26-47, The language Laboratory Association of Japan. 


\section{Conclusion}

One part of the definition of the language laboratory mentioned in the first chapter was "...appropriate teaching materials..." In general, the language laboratory today exists to impart foreign language instruction through mechanical devices, however, its utilization will become more effective when teaching materials are properly designed and presented.

The training of listening and speaking abilities takes many hours and requires a great number of competent teachers experienced in language laboratory techniques. In order to increase efficiency in teaching English, it is important to design the most appropriate types of teaching materials for each teaching target. This should be done on he basis of knowledge about which types of teaching material should be used for the certain teaching objective, and on the basis of to which extent teaching can be done in the language laboratory.

This theme, The Language Laboratory and Teaching English at College level, is not completed by the above discussion. Rather, it should be followed by a series of studies on class-organization, evaluation, and administration, and with research will be discussed by the authors at a later date.

\section{Northeast Conference} on the Teaching of Foreign Languages

\section{7th Annual Meeting}

\section{OUR PROFESSION: PRESENT STATUS AND FUTURE DIRECTIONS Chairman: John L. D. Clark of ETS}

April 17-20, 1980, at the Now York Hilton Hotel, New York City

Make sure to keep a place open on your calendar and in your budget for the Northeast Conference on the Teaching of Foreign Languages. Join the 2.500 other teachers who will be with us in April to see the latest exhibition of texts. audio-visual. equipment and materials, teaching aids, and study programs.

Discover the state-of-the-art in foreign language teaching at the nation's oldest and largest foreign language conference. For program information write:

Northeast Conference - Box 623 - Middlebury, VT 05753 